\title{
TRAINING TEACHERS IN ROBOTICS FOR SCIENCE AND TECHNOLOGY DISSEMINATION: A BRAZILIAN CASE STUDY
}

\author{
Rafael Marengo \\ Federal University of Lavras (UFLA), Engineering Dept., P.O. Box 3037, ZIP Code 37,200-000, Lavras-MG, Brazil \\ Bruna Fontes Ferreira \\ Federal University of Lavras (UFLA), Engineering Dept., P.O. Box 3037, ZIP Code 37,200-000, Lavras-MG, Brazil \\ Morgana Reis Cabral \\ Federal University of Lavras (UFLA), Engineering Dept., P.O. Box 3037, ZIP Code 37,200-000, Lavras-MG, Brazil
}

\author{
Ricardo Rodrigues Magalhães \\ Federal University of Lavras (UFLA), Engineering Dept., P.O. Box 3037, ZIP Code 37,200-000, Lavras-MG, Brazil \\ Corresponding author: ricardorm@deg.ufla.br
}

\begin{abstract}
There is a high demand for technical professionals in engineering and related areas, but there are not enough professionals to fill these needs, especially in developing countries such as in Brazil. Abilities of communication, teamwork and leadership are part of the graduating engineers' curriculum, but students normally have a lack of these abilities due to difficulties in STEM (Science, Technology, Engineering and Mathematics). Many solutions can be implemented in order to change this scenario and robotics is an alternative. Based on that, robotics education as teaching methodology leads students to search for problem logical solutions. This paper is aimed on how robotics can help children learn STEM subjects and presents a training system for robotics involving teachers and students from public schools and tutors from university. As methodology, it was tested the knowledge acquired in weekly meetings between engineering students (tutors) and teachers/students from public schools. Results highlighted the introduction of robotics education in public schools learning process. It can imply on improvements for engineering courses and new robot applications in industries.
\end{abstract}

Index terms: STEM, robotics education, public schools, technology.

Received: August, 20, 2018 - Accepted: January, 27, 2019

\section{INTRODUCTION}

Machines can help production development and they are created to make things faster and less complicated. However, machines are not able to learn by themselves. For example, if a computer is able to teach or pass information, it is because this has already been taught to it by a human being (Papert, 1980). Although there are several findings related to affective computing, there is a lack of research that analyses and summarizes their impacts, contributions and applications (Reis et al., 2018).

Programming is nowadays considered one of the most feared subjects for engineering courses. This is because programming is something completely new for students, mainly for children from elementary school and other levels. Consequently, many students had never programmed before enter to the university. However, if students learn programming basics while they still are in schools, this subject would become more common and, therefore, easier and less feared. One of the best ways to introduce programming in schools is by using robotics (Gallagher, 1994; Barakat, 2011).

A problem for implementing robotics as a subject in public schools is how much this project would cost. Lego robotic kit, for instance, costs approximately $165 \%$ of Brazil's minimum monthly. However, this problem could be solved by alternative kits, such as Arduino (that is an open source platform. But it involves systematic training teachers for students' dissemination.

The aim of this paper is to present the approach taken by students from university technical courses with the intention to capacitate teachers from public schools in robotics. Results showed 
that the introduction of robotics education for public schools, in the city of Lavras - Brazil, can be a solution for learning process by means of weekly meetings between graduating engineers (tutors) and teachers/students from schools.

This paper is divided into five sections: besides this introduction section, section 2 presents the theme background, material methods are presented in the section 3 , results and discussion are presented in the section 4 and section 5 presents the conclusions.

\section{Background}

In the beginning of technology's history, Science, Technology, Engineering and Mathematics (STEM) (Christie et al., 2017) was used for helping children and young people for choosing technical areas. This helped them to develop abilities in order to solve problems. In this context, developing countries are working to improve STEM in schools in order to motivate students about careers in engineering areas as result of a lack of specialists in STEM areas (Mondata, 2016).

Diverse learning opportunities and deep engagement are needed to support development of engineering competencies and expertise (Siddique et al., 2015). Therefore, if a subject is learnt but not applied, it may be forgotten. However, the needs to have a deep understanding of the subject and assimilate it for dissemination are real challenges.

Introducing robotics in schools as a subject would help students to be more confident when choosing technology related careers and it would be an efficient way to teach physics and mathematics for children. Pre-defined actions and computer programs are basic mathematical operations. Teaching physics and mathematics related to robotics makes the learning process more natural because it is different from regular classes and it is unconscious. In this case, students are aware that they are learning robotics, but most of them are not aware that they are learning physics and mathematics as well. Papert (1980) presents that learning mathematics through robotics is similar to learning French in France, it is an unconscious process. But for teachers that have been working for years using same methods, it is a real challenge to teach subjects completely new to them, although it is possible with proper training (Cejka et al., 2006).

One of the most used educational robotics kit is the Lego (Leal et al., 2017; Cuevas et al., 2010). This educational kit is composed by regular building parts, motors, sensors and a programmable HD which is the microcontroller. Robot kits can be assembled in easy way and students normally have fun during robots' assembly and programming outside classrooms. This makes students more open for learning subjects considered with some degree of difficulty (Kelly, 2010).

Lego Mindstorms ${ }^{\circledR}$ platform allows students to learn important concepts related to engineering, physics, mathematics and many other areas without difficulties. Using Lego, children can create complex models that would be very hard using regular disciplines, such as math and physics.

Lego Mindstorms ${ }^{\circledast}$ components are plug in play, which makes everything easier for those who have never had previous contact with this kind of technology. The main processing unit allows the connection to four sensors and four actuators simultaneously, which is considered enough for educational robotics' purpose.

The language used for programming from most of robots kits is a block programming language that is considered the best way for beginners. Lego uses visual language where students can drag blocks across the screen and place them in a logical order. These blocks are drawing on specifying which component is controlled. For instance, a block that has a motor drawn on it, control the motor's speed and direction. This language is simple and easy to understand, but it forces the programmer to describe actions in a highly detailed and organized way, which is the way the most used computer languages are structured (Kelly, 2010).

Arduino $^{\circledR}$ platform is more complex to understand, that is a microcontroller which allows coding in $\mathrm{C}$ programming language (Ramos et al., 2018). There are a lot of sensors and actuators that can be used together this platform, turning it into a versatile and cheap alternative for building educational robots. Although build a robot by using Arduino platform is harder 
than Lego, there are some advantages, such as the price, open source codes and flexibility of this technology.

Teachers that have never had any contact with programming before can find it more difficult than others. This is one of the reasons why students should be familiarized with programming at an early age. Unfortunately, this is the reason there are few teachers that find themselves capable of teaching programming in schools.

According to Kazakoff (2013) and Elkinet al. (2014), in Medford, MA - USA, workshops were provided every summer for teachers during four years, in order to teach basic concepts of science and engineering, engineering design process, Lego building techniques and programming. Those workshops were provided with the intention of making teachers capable of bringing robotics and engineering into their own classrooms. As result, although some of the teachers preferred to continue their classes without robotics, most of teachers adopt robotics into their classrooms and their students showed that they could retain a significant proportion of contents, process and knowledge. This indicates that students are capable for understanding science and engineering concepts at a young age when they are engaged in relevant robotics project (Cejka et al., 2006).

\section{MATERIAL AND METHODS}

\section{Methodology adopted in the project}

Seven public schools from the city of Lavras - Brazil were involved in this project and each school participated with at least one teacher and one student through weekly meetings between them and five engineering students (tutors). Some schools chose teachers related to technology areas, but others chose Biology, Portuguese language and Arts teachers as well. According to Barron et al. (2011), teachers from a variety of different backgrounds have become interested in finding ways to incorporate new technology into their curricula. Figure 1 shows the scheme of methodology adopted in this project.

A computer laboratory from the University of Lavras - Brazil was used to support the activities in this project. Weekly meetings happened once a week during 4 hours a day, in a total of 8 weeks. The classes had the following content:

a) Basic algorithm structures (1 week): Firstly, it was presented some programming languages basic concepts.

b) Robot structure (1 week): The second step was to show which kind of robot assembly could help the accuracy and execution of the tasks.

c) Actuators (1 week): An overview on which kind of actuators (motors) should be used on the robots and how they work was provided during this step.

d) Sensors (1 week): An overview on the kind of sensors should be used for robots to perform the proposed tasks (IR, Ultrasonic, LDR and push sensors) was provided during this step.

e) Lego IDE - Integrated Programming Environment (1 week): Blocks assembly principles (move an actuator, turn the motor, speed change, direction and time functioning, reading sensors, detecting colours and distance measuring from ultrasonic sensor) was taught during this step.

f) Advance programming (1 week): Finally, Arduino IDE and $C$ language principles (variables, flux control, loops, functions) were taught.

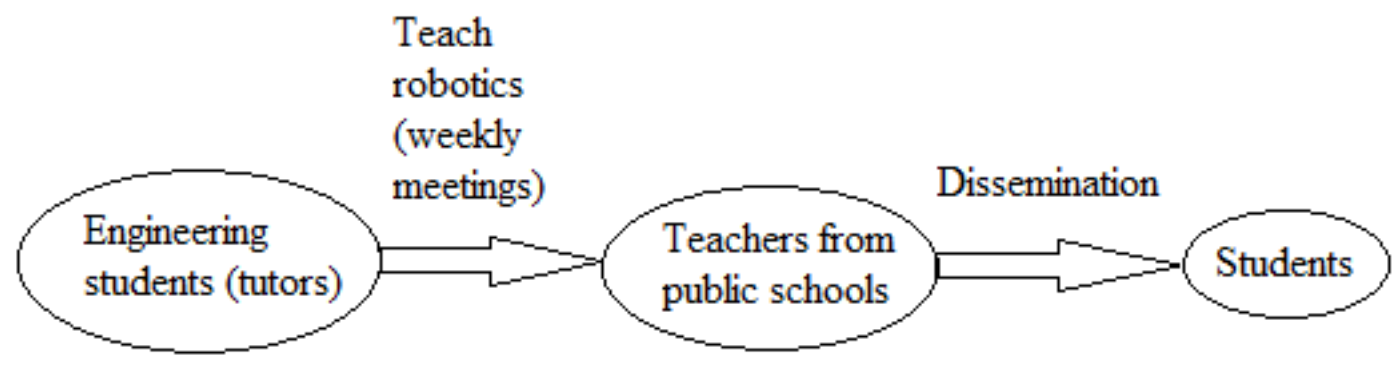

Figure 1: Methodology adopted in the project. 
In the last two weeks, it was performed practical classes to let teachers free for their own robot assembly and programming in order to fix the concepts seen in the previous steps.

\section{Follow line robots programming}

Robotics is divided into two types: fixed and mobile robots (Huang et al., 2019). Line follow line robots are considered mobile robotics. According to Pakdaman and Sanaatiyan (2009), follow line robots are autonomous which have the ability to detect and follow a line using on board hardwired control circuit. Nowadays, to reduce human effort and ensure efficient automatic transport system, follow line robots are becoming popular. Especially in industrial areas, these kinds of robots are used in a large scale. In addition, follow line robots need to provide high efficiency at minimum cost in industries (Chowdhurya et al., 2017).

Lego and Arduino platforms are normally used for follow line robots. They use algorithms based on the $C$ programming language. For this, a trajectory control system was used to improve the performance of the robot. In order to determine a trajectory, it is necessary to know the ideal way to be followed during the route. In this case, a control system works by taking two trajectories into account (desired trajectory and real trajectory), trying to minimize the difference between them, Figure 2.

In this project, teachers used firstly Lego robot to follow lines, because it consists in easy software for developing educational projects and hardware ready to assembly and run. Figure 3 presents teachers first tryouts by using a Lego follow line robot.

In the case of Arduino platform, electronic parts, actuators and sensors were used to assembly the robot. An ultrasonic sensor (HC-SR04 model) was assembled on the front of the robot and three light sensors (TCRT5000 model) were assembled in the robot bottom. In addition, two actuators (servo motors SG90 model) were assembled on the sides of the robot in order to provide movements. Figure 4 represents the first Arduino robot assembled for competition. This robot was developed and assembled by tutors from the University of Lavras - Brazil, helped by a 3D printer.

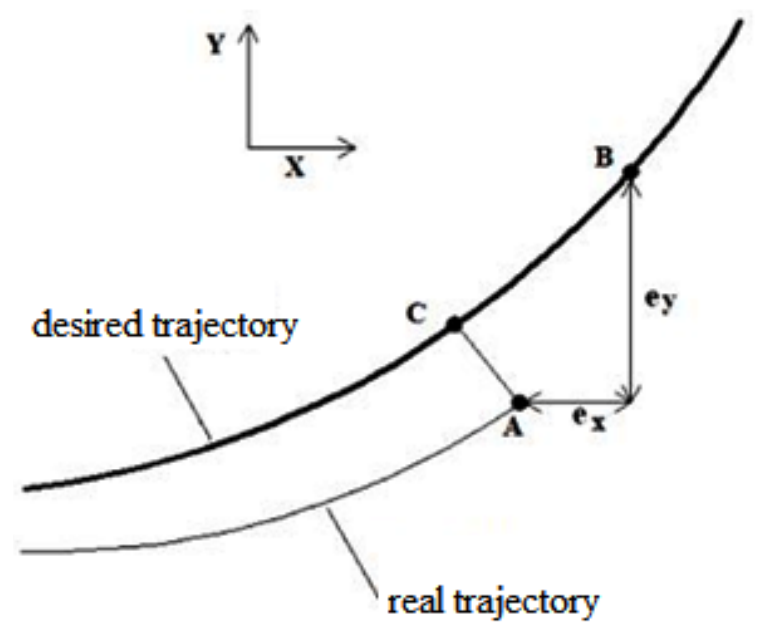

Figure 2: Path Error (adapted from Menezes Filho, 2010).

Legend: $\mathrm{A}$ is the point followed by robots from a real trajectory; $\mathrm{B}$ and $\mathrm{C}$ are desired points to be followed by robots, $\mathrm{e}_{\mathrm{x}}$ is the $x$ axis distance between points $\mathrm{A}$ and $\mathrm{B}$ and $\mathrm{e}_{\mathrm{y}}$ is the $y$ axis distance between points $A$ and $\mathrm{B}$.

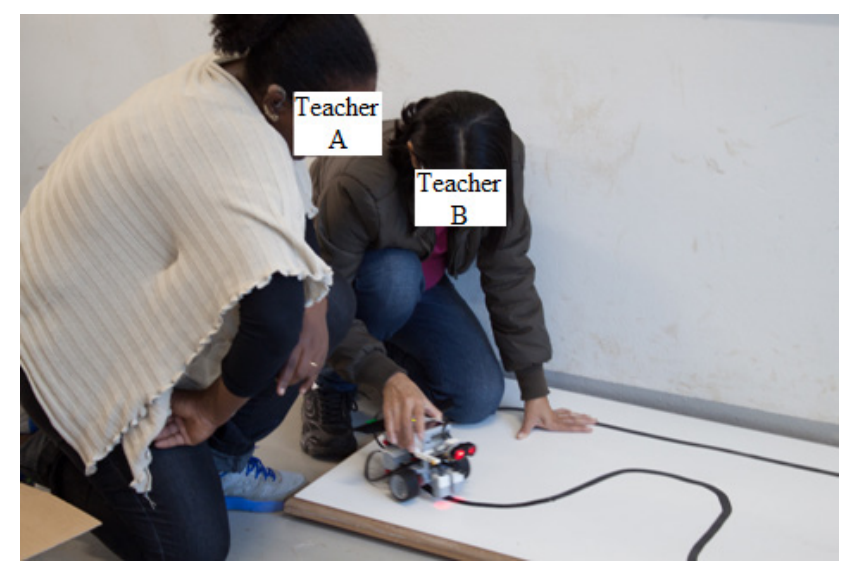

Figure 3: Teachers' follow line Lego robot first tryouts.

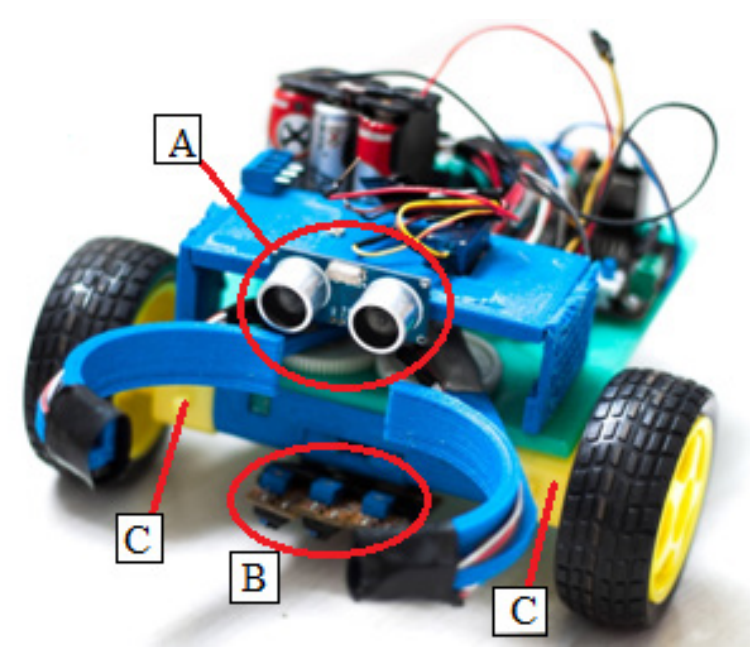

Figure 4: Sensors and actuators position in the robot. (A. Ultrasonic Sensor; B. Light sensors; C. Actuator). 
Based on the sensors and actuators, it was defined the robot direction following the strategy below:

- If the right light sensor receives reflection, then start left motor;

- If the right light sensor (LED) is not reflected (no white light), then turn off the right motor;

- If the LED on the left side from light sensor is not reflected (no white light), then switch off the motor on the left side;

- If the left light sensor receives reflection (white light captured), then start the motor on the right side.

Once robots assembled and programmed, teachers and students started facing similar problems as in the Brazilian Robotics Olympiad OBR (Aroca et al., 2016). To solve the challenges, they used the knowledge acquired in the previous stages of the project (programming learn). At final methodology step, teachers and students developed and programmed their own algorithm.

\section{Methodology implementation in the schools}

From the seven schools that participated of the eight weekly meetings, only two schools wanted to follow the project. In this case, one teacher for each school was designed to accompany student together tutors in both schools for dissemination.

Firstly, students went through a period of preparation in order to perform the mechanical robots' assembly, considering the presentation of the pieces and explanations about basic mechanics, motors' operation, sensors, gears, pulleys and connectors. At this time, students improved their ability to observe and reply.

After robot assembly, students learned sequential logic classes, associating the concept of algorithms with day-to-day situations, since robots' programming may initially appear to be complex. During the first classes, students learned concepts of logic and flowcharts uses as well as an introduction to the functions and operation of Lego Mindstorms NXT $^{\circledR}$ software, in which logical blocks are used to program the robots. Figure 5 shows tutor teaching Lego Mindstorms NXT ${ }^{\circledast}$ software for students at the school. During this step, teachers only accompany the project.

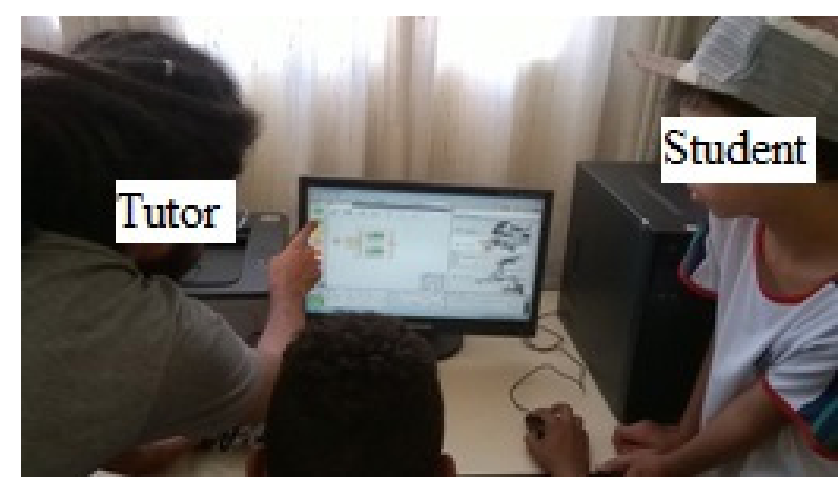

Figure 5: Tutor teaching Lego Mindstorms NXT ${ }^{\oplus}$ software for students at school.

At the first moment, students faced similar problems as they would face in OBR competition. Previously this stage, a runway similar OBR competition was performed by tutors in order to identify issues to solve problems related to robots' programming and assembling. This activity was followed by students and teachers.

The final step was the development of algorithms for the participation in OBR competition. Thus, students worked with more complex algorithms, dealing with failures and frustrations, evidencing the use of the presented tools since, during OBR competition, they worked without tutors and teachers helping. The total timing for the project implementation at schools was 48 weeklies.

Alternative ways for building robots in the schools were exploited when students used Arduino platform. Arduino robots were built using cardboard, pieces of plastic, old CDs or other recyclable materials. This is an incentive for creativity and besides, it is considered an economic way for building robots, since the only parts that need to be bought are electronic components. Figure 6 presents an Arduino follower line robot built by tutors and students which used CDs as the robot chassis.

The project implemented in the schools was called "Educational Robotics for Social Inclusion" and it had the objective of making children learn and be able to recognize that the effort in education has meaning. For capacitating and training the students, teachers and tutors followed the steps below:

a) First, basic algorithm structures were presented to the students by means of web games, flow charts and other resources - 10 weeks; 


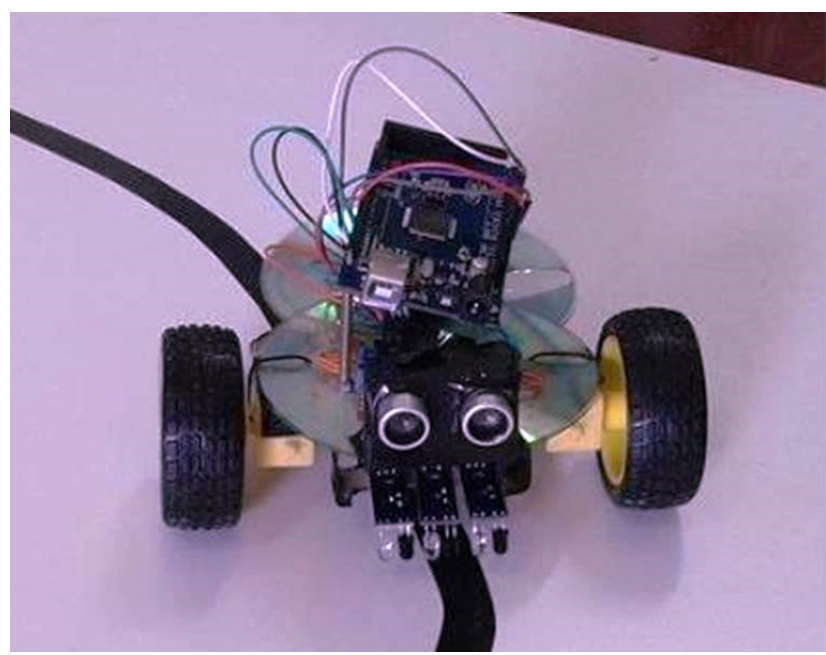

Figure 6: Arduino platform follower line robot CD chassis.

b) Second, teachers and tutors presented to the students, basic concepts on how to work with both platforms (Lego and Arduino) - 2 weeks;

c) After basic concepts, teachers and tutors presented the ways to design and assembly robots by using different materials (plastic, wood, cardboard) - 2 weeks;

d) Fundaments of sensors and actuators used in the robots was presented - 6 weeks;

e) Blocks programming, used for Lego platform was also presented - 8 weeks;

f) Finally, C language programming, used for Arduino platform - 10 weeks.

In the last 10 weeks, it was performed practical classes in order to let students free for the own robots' assembling and programming for the OBR competition.

\section{RESULTS AND DISCUSSION}

In OBR competition, robots must not only follow lines, but also complete a closed loop circuit following a black line and bypassing obstacles in the way. Since 2012, students from public schools from the city of Lavras - Brazil are being prepared for OBR participation, obtaining success (Magalhaes et al., 2015). Figure 7 shows a student under evaluation in a regional OBR competition.

Considering the implementation of this project in public schools from the city of Lavras - Brazil, it was observed during the weekly meetings an improvement in their logical reasoning, a greater interaction with their colleagues, teachers and tutors, greater interest in activities and the use of creativity for learning.

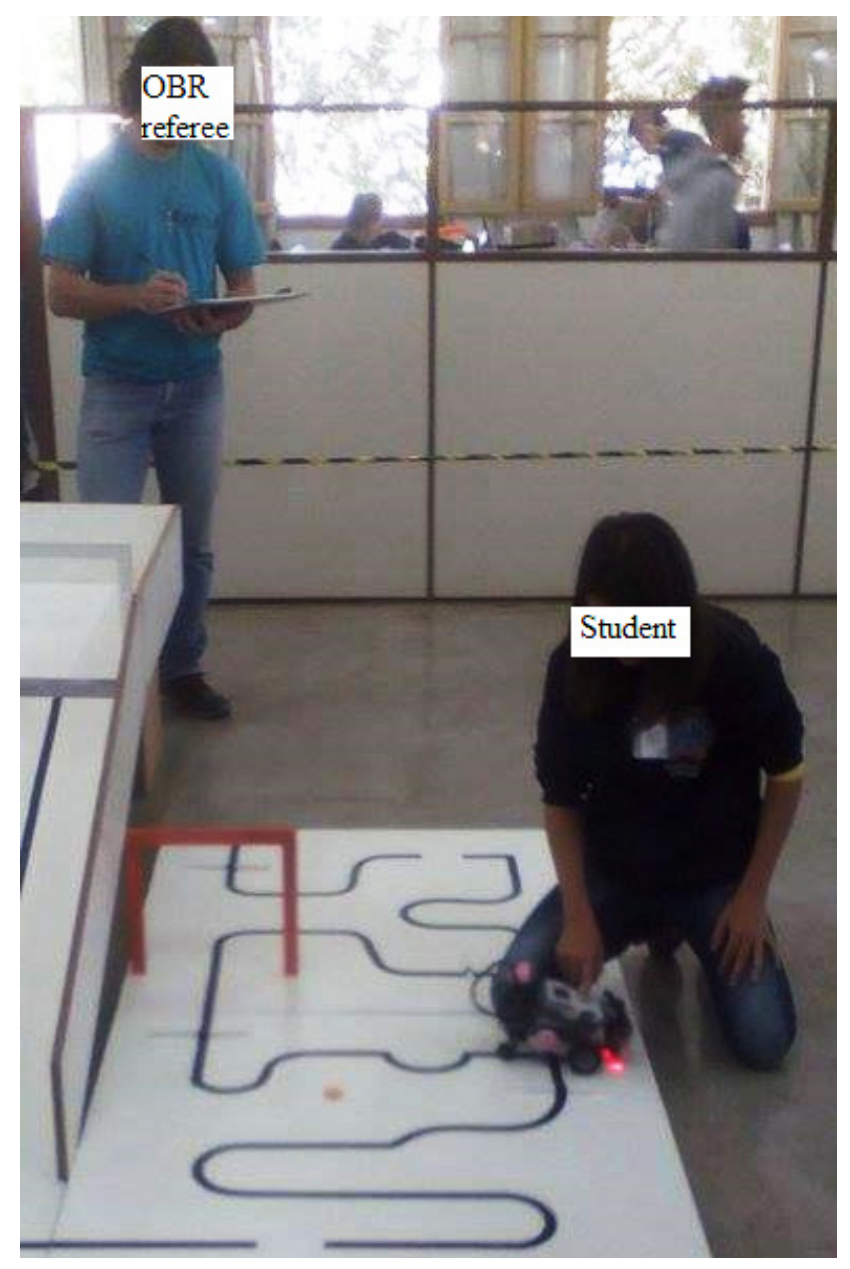

Figure 7: Student in a regional OBR competition.

In addition, Lego and Arduino platforms as teaching tool for children from elementary schools was efficient in a multidisciplinary aspect, where the students' intellectual and social development was the main focus. It was also noted the students' ability to socialize and develop cooperative work, both in contributions to robot design and programming. Those abilities are essential for future engineers' career development.

This development could be observed in the regional OBR competition 2017 edition, in which three teams from 4 th and 5th grade from an elementary school were the only team in the competition that used Arduino platform at level I (only elementary school children). Students showed, despite their young age, ability to deal a lot of problems during the competition without any help from the tutors and teachers. The team 
also exhibited attributes such as joint interactivity, agility in solving logical challenges and creative solutions. Even though students did not score satisfactorily in this year's competition, students were motivated to compete again, showing that the goal of the project was achieved.

A negative aspect for the implementation of this project is the fact of only two teachers wanted to follow the project in the schools and also, they are not capable to teach robots for students by themselves. In this case, they are supported by tutors from university. Possible reasons for this take place can be the short training period in robotics or even lower salary versus working overtime availability. One alternative to solve that is to perform workshops, as in Medford USA, for teachers during four years, providing Lego and Arduino building techniques and programming, but it would cost a lot. Another alternative would be the salary increase for those teachers who are interested on robotics as the way to motivate them. In this case, they need to work out of regular timing in order to prepare the robotic classes.

In other hand, some positive points can be noted as effects for the implementation of this project, such as:

- Students become more interested in learning and applying knowledge for real world problems, they easily develop the ability of managing situations, organizing ideas, working in teams and knowing basic procedures for working in projects. All these abilities are essential for anyone that seeks a successful career in engineering areas.

- Some schools that participated for this project are located in periphery region from the city of Lavras - Brazil and children live into high-risk social positions. This project allowed students to be at school in a full-time period, which reduces the chance of them getting involved with common issues from these areas, such as drugs, violence and other issues. It means that this project is not only a technological activity but also a social inclusion. In addition to that, letting students work on this project becomes an incentive them to join universities and follow technical carriers.

- This project also provided the interaction between schools, university and society, which can be considered an advantage in terms of regional industrial development.

\section{CONCLUSIONS}

This paper presented a methodology used in public schools that allows students to solve problems by using the knowledge acquired from executing tasks using robots. It is not just building robots, this project helped children to solve real problems, dealing challenge situations and able to work in team. This methodology also helped public schools to cease conventional classes presented an environment and full of interactions, filled with many learning opportunities and possibilities. Helped by this project, learning stopped being to be a single memorizing action and teaching started to be more than repeating pre-ordained content.

It is also noted that the use of projects for educational purposes is functional because the students are able to link the act of learn as a virtuous thing. In this context, this project showed how an idea can grow, turn into an action and change everything and everyone around it, even if they are not directly involved. This becomes clear when the school assumed more responsibility than just teaching. In the absence of a family support, the school becomes an identifier for personal problems and social risk. The school can be seen as the communities' support, capable of giving directions to students, causing an unexpected improvement into the area.

Contributions of this work were not only for students that participated in the schools, but also for the engineering students (tutors) and teachers. Teachers and tutors not only taught, but could learn as well. Technically, they have been able to learn or improve their programming language skills, but more specifically, with Arduino platform, which has been increasingly used both in academia and industries. In behavioural terms, teachers and tutors were able to have experiences of social differences, thinking and teamwork, as well as they had the opportunity to follow students for participating from an academic competition. It can imply on skills improvements for their carriers. 


\section{REFERENCES}

AROCA, R. V. et al. Brazilian Robotics Olympiad: A successful paradigm for science and technology dissemination. International Journal of Advanced Robotic Systems, 1-8, 2016.

BARAKAT, N. Balanced Integration of Theory and Applications in Teaching Robotics. International Journal of Mechanical Engineering Education, 39, 195-206, 2011.

BARRON, B. et al. Take a giant step: A blueprint for teaching children in a digital age. New York: The Joan Ganz Cooney Center at Sesame Workshop, 2011.

CEJKA, E., ROGERS, C.; PORTSMORE, M. Kindergarten Robotics: Using Robotics to Motivate Math, Science, and Engineering Literacy in Elementary School. The International Journal of Engineering Education, 22(4):711-722, 2006.

CHOWDHURYA, N. H.; KHUSHIB, D.; RASHIDC, M. Algorithm for Line Follower Robots to Follow Critical Paths with Minimum Number of Sensors. International Journal of Computer, 24 (1):13-22, 2017.

CHRISTIE, M. et al. Understanding why women are under-represented in Science, Technology, Engineering and Mathematics (STEM) within Higher Education: a regional case study. Production, 27(spe), 2017.

CUEVAS, E., ZALDIVAR, D., PÉREZ-CISNEROS, M. Low-cost commercial Lego $^{\mathrm{TM}}$ platform for mobile robotics. International Journal of Electrical Engineering Education 47(2):132-150, 2010.

ELKIN, M., SULLIVAN, A., BERS, M. U. Implementing a robotics curriculum in an early childhood Montessori classroom. Journal of Information Technology Education: Innovations in Practice, 13:153-169, 2014.

GALLAGHER, S. A. Middle school classroom predictors of science persistence. Journal of Research Science Teaching. 31(7):721-734, 1994.

HUANG, H. et al. Mobile robots in wireless sensor networks: A survey on tasks, Computer Networks, 148:1-19, 2019.

KAZAKOFF, E., SULLIVAN, A.; BERS, M. U. The effect of a classroom-based intensive robotics and programming workshop on sequencing ability in early childhood. Early Childhood Education Journal, 41(4):245-255, 2013.

KELLY, J. LEGO mindstorms NXT-G programming guide. 2nd ed. New York, NY: Apress, 2010.

LEAL, F. et al. Learning lean with lego: developing and evaluating the efficacy of a serious game. Production, 27(spe), 2017.

MAGALHAES, R. R., MARENGO, R.; FERREIRA, N. J. Robótica educacional para inclusão social: relato de uma experiência extensionista em Lavras/MG. Revista Ciência em Extensão, 11(3):120-131, 2015.

MENEZES FILHO, J. B. Neural and Vectorial Controller for XY Table. Revista Controle \& Automação, 21(4): 406-424, 2010.

MONDADA, F. et al. Robotics to integrate educational efforts in South Africa and Europe. International Journal of Advanced Robotic Systems, 1-13, 2016.

PAKDAMAN, M., SANAATIYAN, M. M. Design and Implementation of Line Follower Robot. Computer and Electrical Engineering, 2: 585-590, 2009.

PAPERT, S. MINDSTORMS: Children, Computers, and Powerful Ideas, New York: Basic Books, 1980, p.3-18.

RAMOS, A. D. et al. Uso da plataforma arduino na interdisciplinaridade do Ensino Fundamental I: Relato extensionista em uma escola pública. Extensão em foco, 17:120-132, 2018.

REIS, R. C. D. et al. Affective states in computersupported collaborative learning: Studying the past to drive the future. Computers \& Education, 120:2950, 2018.

SIDDIQUE, Z. HARDRE, P. L.; ALTAN, D. Effects of a mechanical engineering design course on students' motivational features. International Journal of Mechanical Engineering Education, 43(1):44-74, 2015. 